\title{
PRODUÇÃO ENZIMÁTICA DE BIODIESEL ETÍLICO EM REATOR DE LEITO FIXO E FLUXO CONTÍNUO UTILIZANDO CÉLULAS INTEGRAS DE Mucor Circinelloides IMOBILIZADAS EM ESPUMA DE POLIURETANO
}

\author{
A. L. L. RICO ${ }^{1}$, H. F. DE CASTRO ${ }^{1}$ e P. C. OLIVEIRA ${ }^{1}$ \\ ${ }^{1}$ Escola de Engenharia de Lorena - USP, Departamento de Engenharia Química
}

RESUMO - O presente trabalho teve como objetivo avaliar os parâmetros de síntese (tempo espacial e razão molar) do biodiesel etílico de babaçu, produzido em reator de leito fixo e fluxo contínuo, utilizando células íntegras de Mucor circinelloides imobilizadas em espuma de poliuretano. Quatro razões molares (1:4, 1:6, 1:8 e 1:12) e três tempos espaciais $(12 \mathrm{~h}, 24 \mathrm{~h}$ e $60 \mathrm{~h})$ foram testados. Amostras foram retiradas a cada $24 \mathrm{~h}$ durante um período de 12 a 16 dias e submetidas à análise por cromatografia gasosa para determinação do perfil dos ésteres etílicos. Rendimentos da ordem de $64 \%$ foram obtidos na razão molar 1:6 e tempo espacial de $60 \mathrm{~h}$.

\section{INTRODUÇÃO}

A escassez das reservas de petróleo, associado ao crescente aumento do preço dos combustíveis fósseis e da poluição ambiental, torna urgente a procura por combustíveis de fontes renováveis que possam ser inseridos na matriz energética mundial. Dentro deste contexto, surge como uma opção tecnológica interessante o biodiesel, biocombustível com propriedades muito semelhantes as do óleo diesel e que além de ser renovável é biodegradável e possui baixa toxidade (Nasir et al., 2013).

Tradicionalmente produzido pela rota química com elevados rendimentos, o biodiesel tem sido amplamente pesquisado pela rota enzimática, que apresenta, como uma das principais vantagens, a eliminação de parte das etapas de separação do produto formado. Entretanto, baixa produtividade e alto custo de produção em consequência da necessidade de procedimentos complexos para a purificação das enzimas, tem tornado o processo inviável para a aplicação industrial. Dessa forma, a utilização de células íntegras com lipases intracelulares empregadas como biocatalisador em reatores contínuos que apresentam baixo custo e alta eficiência, são opções para otimização do processo de produção de biodiesel enzimático (Andrade et al, 2012; Christopher, Kumar e Zambare, 2014).

A partir do panorama apresentado, o presente trabalho teve como objetivo estudar dois parâmetros de síntese na produção enzimática de biodiesel etílico a partir de óleo de babaçu em reator de leito fixo e fluxo contínuo utilizando células íntegras de Mucor circinelloides como biocatalizador. 


\section{MATERIAIS E MÉTODOS}

\subsection{Materiais}

Espumas de poliuretano (EPUs) foram sintetizadas na EVONIK ${ }^{\circledR}$ com densidade de $19,8690 \pm 0,8403 \mathrm{~kg} \cdot \mathrm{m}^{-3}$ (100 g de Lupranol 3040, 52g de Tolueno diisocinato com $80 \%$ de isômero 2,4 e 20\% de isômero 2,6, 0,8 $\mathrm{g}$ de Tegostab 8228, 0,18 g de Tegoamin 75, 0,12 $\mathrm{g}$ de Kosmos 29 e 4,025 g de água). A linhagem do fungo Mucor circinelloides URM-4182 foi adquirida da micoteca da Universidade Federal de Pernambuco. Como materiais de partida foram utilizados óleo de babaçu refinado (Mundo dos Óleos), etanol anidro 99,8\% e terc-butanol 99\% (Cromoline). Os demais reagentes utilizados foram de grau analítico.

\subsection{Métodos}

\section{$\underline{\text { Preparo do biocatalisador }}$}

As células íntegras foram preparadas pela inoculação asséptica de $10^{6}$ esporos do fungo em Erlenmeyers de $250 \mathrm{~mL}$ contendo 100 cubos de $6 \mathrm{~mm}$ de aresta e $100 \mathrm{~mL}$ de meio de cultura composto por: $70 \mathrm{~g}$ de Peptona, $1 \mathrm{~g}$ de $\mathrm{NaNO}_{3}, 1 \mathrm{~g}$ de $\mathrm{KH}_{2} \mathrm{PO}_{4}, 0,5 \mathrm{~g}$ de $\mathrm{MgSO}_{4} .7 \mathrm{H}_{2} \mathrm{O}, 30 \mathrm{~g}$ de azeite de oliva e 1L de tampão Citrato $\mathrm{pH} 4,5$. Os experimentos foram conduzidos por $96 \mathrm{~h}$ na temperatura de $35^{\circ} \mathrm{C}$ com agitação orbital de $170 \mathrm{rpm}$. A biomassa imobilizada foi separada do meio de cultura por filtração a vácuo, lavada com acetona e seca em bomba de alto vácuo. Ao final do processo, foi determinada a atividade hidrolítica do biocatalisador de acordo com o método de Andrade et al. (2012).

\section{Produção de biodiesel}

As reações em fluxo contínuo foram conduzidas em reator de leito fixo (diâmetro interno = $44 \mathrm{~mm}$, comprimento $=56 \mathrm{~mm}$ e volume total $=85 \mathrm{~cm}^{3}$ ) com o auxílio de uma bomba peristáltica (SJ-1211-L ATTO ou SJ-1211-H ATTO), operando em vazões de 0,0163 mL min ${ }^{-1}$, $0,0408 \mathrm{~mL} \mathrm{~min}^{-1}$ e $0,0815 \mathrm{~mL} \mathrm{~min}^{-1}$, por um período médio de 14 dias. A mistura reacional foi composta por óleo de babaçu e etanol (razão molar 1:4, 1:6, 1:8 ou 1:12 óleo/etanol) e tercbutanol como solvente (razão volumétrica 1:1,5 óleo/terc-butanol). O sistema foi mantido à temperatura de $35^{\circ} \mathrm{C}$. A coluna foi empacotada com 120 unidades cúbicas de biomassa imobilizada correspondendo a um volume de $25,92 \mathrm{~cm}^{3}$ e em seguida estabilizada pela recirculação do substrato através da coluna por um período de $24 \mathrm{~h}$, eliminando bolhas de ar formadas durante a etapa do empacotamento da coluna. $\mathrm{O}$ tempo de residência foi calculado de acordo com Levenspiel (1972). Os ésteres etílicos formados foram quantificados por análise de cromatografia gasosa através de alíquotas retiradas diariamente (Urioste et al., 2008). 


\section{RESULTADOS E DISCUSSÃO}

As Figuras 1a e 1b mostram, respectivamente, os resultados dos experimentos conduzidos na razão molar de 1:6 quanto aos rendimentos de transesterificação $v s$ tempo com variação da vazão e rendimento de transesterificação $v s$ tempo espacial.

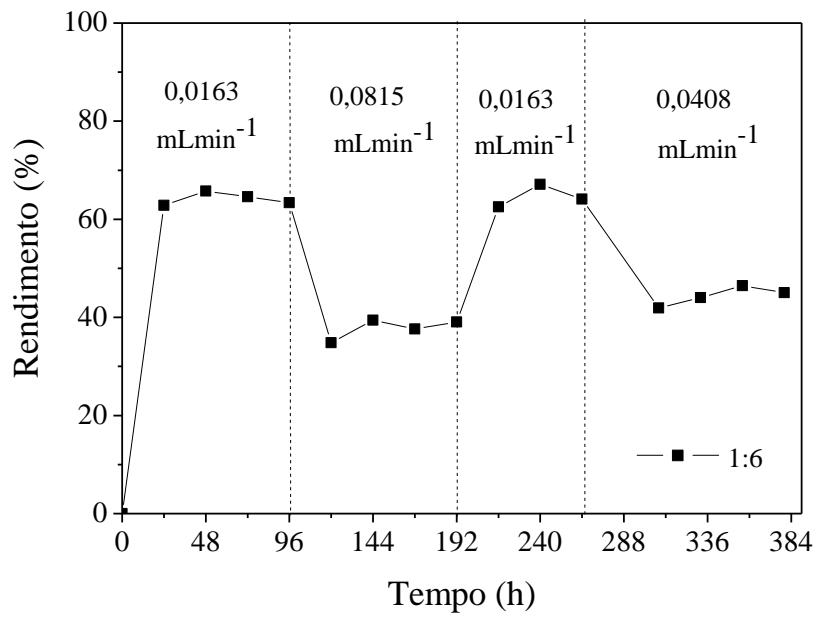

(a)

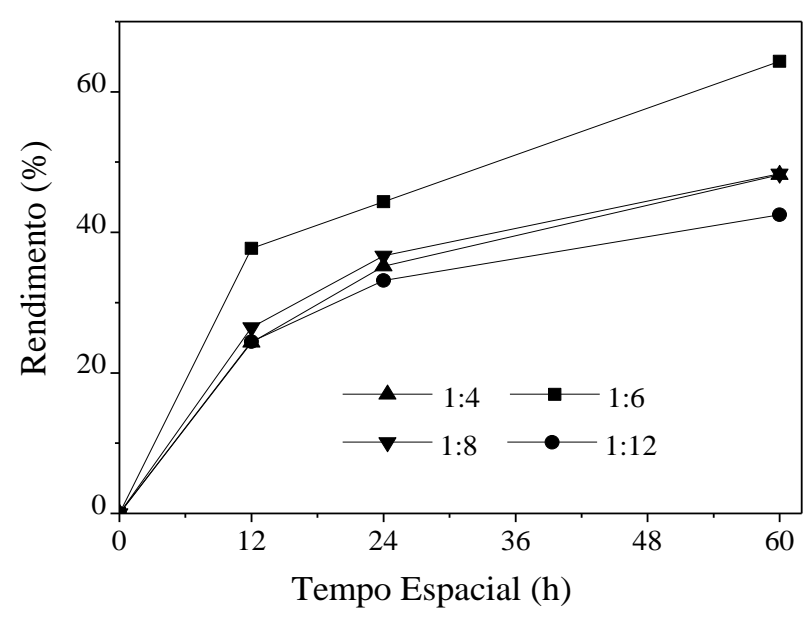

(b)

Figura 1 - a) Rendimentos de transesterificação em função do tempo para razão molar óleo:álcool de 1:6 em diferentes vazões e b) Rendimento médio em função do tempo espacial para razões molares de 1:4, 1:6, 1:8 e 1:12.

Na Figura 1a pode ser observado que o aumento na vazão da ordem de cinco vezes e o retorno ao valor original não afetou o rendimento operacional, indicando boa estabilidade do sistema. $\mathrm{Na}$ Figura $1 \mathrm{~b}$ observa-se que os experimentos apresentaram comportamentos lineares quanto ao aumento do rendimento médio $v s$ tempo espacial. O melhor rendimento foi atingido na razão molar de 1:6. Os experimentos foram analisados no programa Minitab 16.0 quanto ao comportamento estatístico. $\mathrm{O}$ gráfico de probabilidade de $\mathrm{R}$ apresentou comportamento normal e, portanto, não será apresentado neste trabalho. $\mathrm{O}$ gráfico de efeitos principais pode ser observado na Figura $2 \mathrm{a}$. Pode ser verificado que com relação ao tempo espacial, o aumento do rendimento ocorre de forma linear, de maneira que o maior tempo espacial corresponde ao maior rendimento para todos os experimentos. Portanto, o tempo espacial de $60 \mathrm{~h}$, dentro das condições estudadas, foi o tempo que apresentou maiores valores para a variável resposta rendimento. Quanto ao parâmetro razão molar, o comportamento tende a formar uma superfície gaussiana, sendo o ponto de máximo o correspondente ao da razão molar 1:6. 


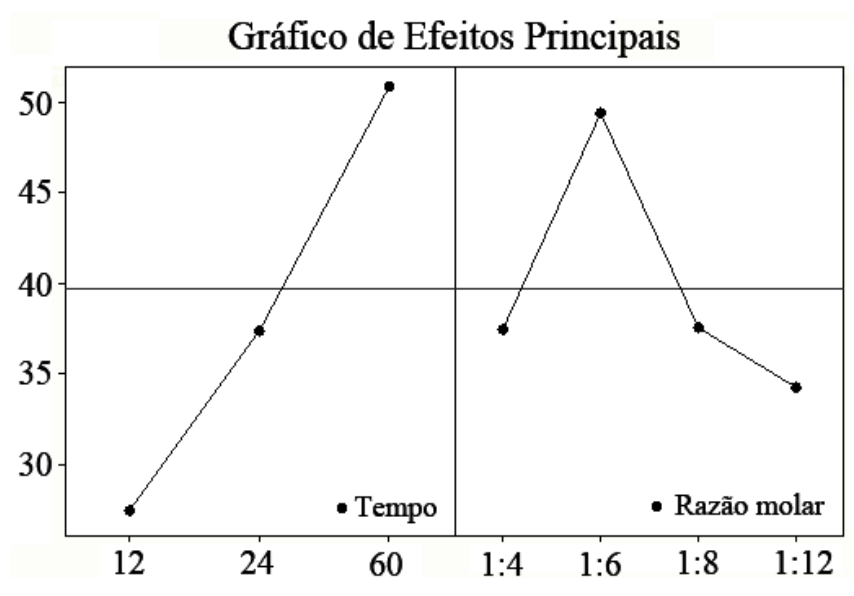

(a)

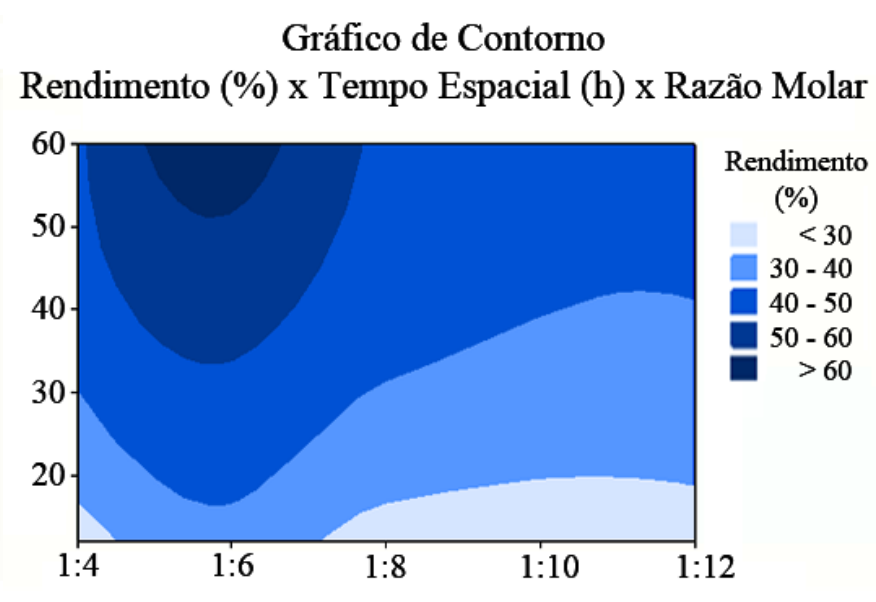

(b)

Figura 2 - a) Gráfico de Efeitos Principais, b) Gráfico de Contorno de R vs Tempo vs Razão Molar

Para analisar os resultados de forma conjunta foi plotado o gráfico de contorno do rendimento $v s$ tempo espacial $v s$ razão molar, apresentado na Figura 2b. Observa-se que o rendimento aumenta progressivamente da região mais clara para a região mais escura do gráfico. Portanto, a região mais escura representa as melhores condições para realização da reação de produção de biodiesel: tempo espacial de 60h e razão molar de 1:6. Estes dados estão de acordo com os do gráfico de efeitos principais (Fig. 2a).

Dos resultados ora discutidos, observa-se que o melhor rendimento, da ordem de $64 \%$, foi obtido em um tempo espacial de $60 \mathrm{~h}$ e razão molar álcool:óleo de 1:6 com produtividade calculada em $8,14 \pm 0,21 \mathrm{mg}_{\text {éster }} \mathrm{g}^{-1}$ meio $\mathrm{h}^{-1}$. Os resultados obtidos são similares aos encontrados na literatura, comprovando assim a eficiência do processo (Andrade, 2012). Entretanto, diversos estudos sugerem que o rendimento e a produtividade em reator de leito fixo podem estar associados com as dimensões do reator, indicando que quanto maior a razão diâmetro:altura maior a produtividade até um limite de 1:14 (Damstrup, 2007). Como a razão do reator utilizado foi de 1:1,27, a otimização na razão diâmetro:altura pode ser interessante para ser verificada em trabalhos futuros.

\section{CONCLUSÃO}

Dentro da faixa de valores estudada, a reação de transesterificação em reator de leito fixo em sistema contínuo com tempo espacial de $60 \mathrm{~h}$ correspondente a uma vazão de $0,0163 \mathrm{ml} \mathrm{min}^{-1}$, razão molar óleo:álcool de 1:6, foi a que apresentou maiores rendimentos, da ordem de $64 \%$. O resultado de produtividade em torno de $8,14 \pm 0,21 \mathrm{mg}_{\text {éster }} \mathrm{g}^{-1}$ meio $\mathrm{h}^{-1}$ pode ser melhorado em função de um estudo que leva em consideração a razão diâmetro:altura na configurações do reator. 


\section{REFERÊNCIAS}

ANDRADE, G. S. S.; Produção de biodiesel a partir de óleos vegetais usando Células Integras imobilizadas de Fungos Filamentosos com elevada atividade lipolítica (Glicerol Éster Hidrolase E.C. 3.1.1.3.) 158 p. Tese (Doutorado em Biotecnologia Industrial) - Escola de Engenharia de Lorena, Universidade de São Paulo, Lorena/SP, 2012.

ANDRADE, G. S. S.; FREITAS, L.; OLIVEIRA, P. C.; DE CASTRO, H. F.; Screening, immobilization and utilization of whole cell biocatalysts to mediate the ethanolysis of babassu oil. J. Mol. Catal. B: Enzym. v. 84, p. 183-188, 2012.

CHRISTOPHER, L. P.; KUMAR, H.; ZAMBARE, V. P. Enzymatic biodiesel: Challenges and opportunities. Appl. Energ., v.119, p.497-520, 2014.

DAMSTRUP, M. L; KIIL, S; JENSEN, A. D; SPARSO, F. V; XU, X. Process development of continuous glycerolysis in an immobilized enzyme-packed reactor for industrial monoacylglycerol production. J. Agric. Food Chem., v. 55, p 7786-7792, 2007.

NASIR, N. F.; DAUD, W.R.W.; KAMARUDIN, S. K.; YAKOOB, Z. Process system engineering in biodiesel production: A review. Renew. Sust. Energy Rev. v. 22, p. 631-639. 2013.

URIOSTE, D.; CASTRO, M.B.A.; BIAGGIO, F.C.; BIAGGIO; DE CASTRO, H.F. Síntese de padrões cromatográficos e estabelecimento de método para dosagem da composição de ésteres de ácidos graxos presentes no biodiesel a partir do óleo de babaçu. Quim. Nova. v. 31. p. 407-412. 2008. 